\section{Acolhimento de Qualidade: Fator Diferenciador para o Incremento do Turismo}

\section{Biagio M. Avena ${ }^{1}$}

RESUMO: Apresenta as caracteristicas básicas do acolhimento que deveria ser oferecido pelos destinos turísticos e os seus equipamentos e serviços turísticos. Trabalha o conceito de acolhimento com ênfase em algumas categorias fundamentais, tais como: a necessidade de acolhimento inerente ao homem; a relação homem-espaço; o desejo e as expectativas do cliente; a organização do acolhimento; o sorriso; o local inicial e amplo do acolhimento ao turista; o perfil e a formação do pessoal para o acolhimento.

PALAVRAS-CHAVE: acolhimento, serviço turístico; homem-espaço.

ABSTRACT: This paper presents the basic characteristics of the hospitality that should be offered at the touristic destinations and their touristic equipment and services. It presents the concept of hospitality focusing some fundamental categories such as: the need of hospitality inner to man: The relationship man-space; the desire and the host's hope; the organization of the hospitality: the smile the tourist's hospitality place; the personnel profile and formation for the hospitality.

KEYWORDS: hospitality, tourist service, man, space.

\section{Introduçāo}

Atualmente pode-se estabelecer uma relação entre o fluxo de turistas no mundo e a forma de acolhimento que estes recebem. Ao se ater especificamente no exemplo de dois países, um sul-americano, o Brasil, e um europeu, a França, esta relação fica bastante evidente e bem contrastante. Segundo dados da OMT, de 1998, a França obteve 70 milhões de chegadas de turistas internacionais; por outro lado, em 1998 o Brasil atingiu 4,8 milhões de turistas (Beni, 2000:220-21). A França, que tem uma superfície equivalente àquela do Estado da Bahia e a terça parte da população do Brasil, tem um fluxo internacional de turistas 14,5 vezes maior do que o Brasil (Beni, 2000:220). A partir dessas constatações uma indagação se apresenta: Quais as razões que levam a esta grande disparidade? Há uma relação entre a forma de acolhimento ao turista e o fluxo de turistas?

O Brasil possui uma gama enorme de belezas naturais, um clima propício ao turismo e ao lazer, um povo alegre, gentil etc. No entanto, há falta de infra-estrutura, tanto nas cidades turísticas e com potencial turístico quanto na maioria dos equipamentose serviços turísticos. Já a França, um país com um passado milenar, apresenta muitas belezas naturais, uma história riquíssima e monumentos histórico-artísticos devidamente preservados eutilizados como atrativos turísticos. Além disso, nas suas cidades há uma infra-estrutura adequada a sua população e ao público de turistas que as visitam. Tudo é planejado e executado para satisfazer os desejos e necessidades dos visitantes e para gerar recursos financeiros para a manutenção dos sítios históricos com seus monumentos e atrativos. Verifica-se, também, um sistema educacional que atende às necessidades de formação geral e específicas de cada cidadão. Faz-se, aqui, uma especial menção ao sistema de formação técnica para as profissões direta e indiretamente ligadas ao turismo e à hotelaria.

Em suma, ressalta-se que na França uma particular atenção é dada ao acolhimento ao turista na sua acepção mais ampla e nas especificidades de cada setor. $\mathrm{O}$ objetivo deste trabalho é apresentar o que é o acolhimento e o acolhimento ao turista. Tomam-se por base as seguintes questões: afinal o que é acolher? O que é o acolhimento? Que abrangência tem na França? Será que poderíamos desenvolver essa habilidade para bem acolher o turista nas nossas cidades, nos nossos equipamentos e serviços turísticos e atrair um fluxo maior e melhor de turistas?

Inicialmente, aborda-se o acolhimento lato sensu e em seguida como este deveria ocorrer nos meios de hospedagem. Nesta abordagem analisam-se categorias, tais como:

- necessidade de acolhimento;

- relação homem-espaço;

- desejos e expectativas do cliente;

- organização do acolhimento;

- sorriso;

- local do acolhimento ao turista;

- perfil e a formação do pessoal para o acolhimento ao turista. 


\section{Acolher/Acolhimento: o que é isto?}

Segundo Gouirand (1994) a palavra "acolher" vem do verbo "colher" com o prefixo "a" e nela há a idéia de ação e de vontade e, como na colheita, o acolhimento é um ato voluntário. No sentido figurado, acolher significa, também, concordar, aceitar, e está muito próximo do sentido da palavra recolher. Na idéia de acolher/ acolhimento existe a de reunião, hospitalidade e de caridade. O conceito abaixo expressa todas estas idéias. O acolhimento é:

Um ato voluntário que introduz um recém-chegado ou um estranho em uma comunidade ou um território, que otransforma em membro desta comunidade ou em habitante legítimo deste território e que, a este titulo, o autoriza a beneficiar-se de todas ou parte das prerrogativas que se relacionam como seu novo status, definitivo ou provisório (Gouirand, 1996: 180)

Gouirand (1996) diz que é necessário fazer uma distinção entre acolhimento e serviço, pois se usa uma palavra pela outra. A noção de serviço deve ser explicitada, visto que é, às vezes, injustamente desvalorizada sendo confundida com servilismo (idéia de legalidade ou de costume) ou com servidão (idéia de inferioridade, desonra e falsidade). Ao contrário, servir é frequentemente uma honra. Servir o País, servir as forças armadas e retira-se disso, glória e reconhecimento. Neste contexto a prestação de serviços tem outro conceito, pois quando servimos alguém, não estamos em servilismo, tampouco em um ato de servidão. Nessa prestação somente as habilidades técnicas não são suficientes e a atenção à subjetividade humana é insubstituível. Fazer uma prestação de serviço é substituir aquele ao qual oferecemos este serviço, pela sua impossibilidade ou sua indisponibilidade ou sua ignorância e, assim, pela sua vontade e autorização, agimos no seu lugar.

Em um serviço há a execução de uma atividade por um sujeito no lugar de um outro. Há uma substituição. O acolhimento é completamente diferente da prestação de serviço, pois é uma relação entre duas pessoas que implica a execução de uma atividade com o outro (um recepcionista acompanha um cliente ao seu apartamento. Portanto, não há substituição). No servir, isto é, na ajuda ao outro há algo que eu faço no lugar do outro. No servir a noção de obrigação está excluída - servimos voluntariamente. Estão esses dois elementos presentes no ato do bom acolhimento que implica acolhimento e prestação de serviço, mas não se substitui um pelo outro, são atos necessários e complementares.

Para Gouirand (1996), ambos, o acolhimento e o serviço, fazem parte do produto hoteleiro, mas eles intervêm em momentos diferentes. Geralmente, acolhese primeiro e servi-se em seguida, mas, frequentemente, também servi-se acolhendo. Assim, vê-se que o acolhimento é sem dúvida um dos componentes da troca comercial, ou seja, na venda de um apartamento ou de uma refeição está compreendida forçosamente uma ação de acolhimento.

\section{Necessidade de Acolhimento}

Na visão de Gouirand(1996), o homem é um "animal social", não pode viver só e não suporta o isolamento que lhe é desequilibrante. Os homens dependem uns dos outros para sobreviver e neste processo há sempre a presença do ato de acolhimento. Assim, considera-se o acolhimento uma necessidade natural, biológica e social. Em todo lugar há sempre a necessidade de acolhimento e a vida moderna exacerba essa necessidade. Com o aumento do turismo de massa multiplicaram-se as ocasiões de um "primeiro acolhimento". É neste primeiro momento que se pode inferir a qualidade do serviço que virá a ser prestado. Em poucos instantes aquele que chega elabora uma "idéia" do lugar e das pessoas e, frequentemente, esta idéia vai perdurar. Se este primeiro encontro é ruim, talvez sejam necessários muitos dias para fazer a primeira impressão evoluir. Se este primeiro encontro for bom, poderá mascarar, naquele que chega, certas imperfeições do local de acolhimento.

A necessidade de bom acolhimento é crescente e constante e a esta soma-se uma exigência de qualidade cada vez maior. Isto ocorre provavelmente em virtude das características das sociedades atuais, onde há a preponderância do egoísmo, do individualismo, do isolamento moral e material do homem. Afirma-se que o homem moderno está só e ele sofre com isso. Por isso, o homem procura no "acolhimento mercantilizado", tal como no acolhimento hoteleiro que é um "acolhimento obrigatório", um paliativo as suas frustraç̃es.

O mesmo autor diz que o hoteleiro ou o restaurateur não vende somente um produto material ao cliente, pois considera que no produto que lhe é proposto estão incluídos a amabilidade, o calor humano, o reconhecimento, a hospitalidade, o cuidado. Desta forma, o hotel tornou-se um lugar onde se pode exigir ser bem recebido e bem acolhido; é o lugar onde se espera que a necessidade de acolhimento natural seja satisfeita, tendo esta expectativa aumentado quantitativa e qualitativamente pelas circunstâncias da vida moderna.

\section{Relaçāo Homem-Espaço}

Para Gouirand (1994), o homem que viaja e que é acolhido numa cidade, num hotel, está num novo espaço que lhe é desconhecido. Ele se sente desenraizado. Este homem em viagem não é o mesmo homem do seu ambiente habitual. E, sobretudo, quando ele retorna de uma viagem, ele não é o mesmo de antes, pois a experiência da viagem o faz evoluir, acrescentando um conhecimento ou o fazendo perder uma ilusão. Desta forma, o cliente, que é recebido pelos profissionais da hotelaria, recebe uma influência dupla e contraditória. É isto que torna o acolhimento hoteleiro tão frágil.

Na concepcão de Gouirand (1994) o viajante é um homem desnorteado. Antes de viajar ele é levado a deixar o local onde reside movido por uma diversidade 
de razões. O viajante não deixa o seu domicílio voluntariamente, mas são as circunstâncias que o levam a mudar de lugar. Num lugar desconhecido ele se sente em perigo, por isso se volta para ele mesmo para melhor enfrentar o desconhecido. Este desconhecido provoca automaticamente um reflexo de defesa: "põe-se em guarda". Sem que ele próprio saiba, este cliente que o hoteleiro vai acolher é um ser angustiado. Oreflexo de defesa leva freqüentemente à agressividade que é produzida pelo medo. Por essa razão não se pode, de forma nenhuma, responder à agressividade com agressividade, mas tranqüilizar o cliente que chega. Portanto, o hoteleiro e o recepcionista devem saber interpretar a atitude daquele que chega. Porém, não são só esses os efeitos da viagem sobre o homem. Para ele a mobilidade simboliza a vida e a imobilidade a morte. A viagem simboliza a liberdade, a força. Tem também um elemento de status social. Ela valoriza o homem.

\section{Desejo e Expectativas do Cliente}

A primeira preocupação dos profissionais que atuam na atividade turística é a de atender as expectativas fundamentais de seus clientes. Para Gourand (1994), tratando-se de acolhimento, as expectativas fundamentais são o "reconhecimento, a hospitalidade e o cuidado".

- reconhecimento: o viajante que chega deseja ser reconhecido como um ser humano, isto é, como um ser que é respeitado enquanto ser. Deseja ser reconhecido como aquele que tem consciência de ser - do mais modesto ao mais brilhante, todos temos um status, na vida e carregamos um certo número de sinais distintivos desse status, e queremos ser recebidos com o respeito ao qual estimamos ter direito. Não há nada mais desalentador para um cliente do que ser tratado como um estranho. O cliente não é um qualquer, é uma pessoa que espera receber todas as atenções que pensa que seu novo status lhe dá direito. O cliente tem consciência de quem é ele. Exige que esse status, que ele mesmo se atribuiu pela sua intenção/ expectativa de comprar uma prestação de serviços, seja reconhecido por aquele que o acolhe. O viajante deseja ser reconhecido como aquele que é desejado. Ora, é pelo desejo que o homem toma consciência dele mesmo e quando ele deseja algo, é ele que deseja e não um outro. Assim, no acolhimento desejamos, sobretudo, ser desejados. Este sentimento de querer ser desejado é forte no cliente de um hotel ou de um restaurante, e este serviço é em parte fabricado pelo acolhimento em si mesmo. Ele se constrói na relação cliente-hoteleiro. Por isso, enquanto o desejo material será facilmente satisfeito naquele que quer comprar um objeto, o desejo do cliente de hotel ou do viajante não será jamais totalmente satisfeito por um quarto confortável se ele foi mal-acolhido. Sentir-se o "mal vindo" faz surgir no cliente uma grande frustração, sentir-se desejado, ao contrário, faz nascer uma grande alegria.
- hospitalidade: é um conceito que histórica e antropologicamente acompanha o homem. É o que transforma o estranho em hóspede. Cada hotel é um pequeno mundo, com uma porta de entrada para dentro da qual se espera um clima de ações de aceitação pelo outro, de acolhimento. O hoteleiro não hospitaleiro é aquele que, mesmo vendendo a hospedagem e a alimentação com certa qualidade técnica, continua considerando o viajante como um estranho. Em relação ao viajante, ele tem somente o dever de fazer uma prestação de serviços tecnicamente perfeita. $O$ hoteleiro hospitaleiro é, ao contrário, aquele que pensa além dos laços comerciais. Para ele, entre seu cliente e ele existem laços humanos quase familiares. É certamente uma das expectativas mais fortes da clientela dos hotéis se traduz por um desejo de pertença. Pertença à comunidade do hotel, que como lar temporário deve ter sujeitos que, por um tempo, serão a sua família. Acolher alguém na sua casa, na sua empresa implica preocupar-se com o seu conforto, o que inclui a sua salvaguarda. O cliente espera que o acolhedor, aquele que o hospeda, faça tudo para protegê-lo, mesmo se ele estiver fora do local onde está hospedado. O hoteleiro que procura evitar esta "responsabilidade", e que finge ignorar esta expectativa do cliente, é qualificado de não hospitaleiro ou pior ainda, de profissionalmente incompetente. Nas profissões turísticas e, particularmente, na hotelaria, a expectativa e a exigência de hospitalidade ultrapassam em muito os elementos do conceito inicial de prestação de serviço, pois abrangem a hospedagem e alimentação, que fazem parte da prestação de serviços vendida, chegando até os componentes da hospitalidade antiga: reconhecimento, proteção, aceitação que são talvez a sua essência e que são totalmente gratuitas por sua natureza subjetiva.

- cuidado: o cliente que chega a um hotel tem a necessidade que se ocupem dele "como uma mãe se ocupa de uma criança". O viajante que chega a um hotel estranho pode estar desorientado, sem saber o quê fazer, onde se dirigir etc., o responsável pelo acolhimento deve ocupar-se disso. Isto não é só desejável, mas necessário. O cuidado consiste em guiar aquele que chega para facilitar a sua instalação, dar-lhe todas as informações e oferecer os serviços necessários. O objetivo desse cuidado é fazer com que o cliente não se sinta desnorteado, que ele veja, por meio das atitudes de quem o acolhe, sua vontade de querer recebê-lo e de tornar a sua estada agradável. O hoteleiro tem por responsabilidade guiar os primeiros passos daquele que ele recebe, primeiramente na sua casa - o hotel, depois na cidade. Junto com o seu apartamento, o cliente compra o acolhimento que lhe permite aí chegar e este acolhimento engloba, necessariamente, a ajuda para a sua instalação no hotel e na cidade. E claro que esta necessidade de ajuda varia em função das circunstâncias, das personalidades e das culturas (Gouirand, 1994:31-42). 


\section{Organizaçāo do Acolhimento}

A recepção é como um iceberg: vê-se somente uma pequena parte. Para que a relação entre o cliente que chega e a pessoa que o recebe - recepção: a primeira parte visível do iceberg - seja boa, é necessário que um enorme trabalho de gestão e de administração seja feito - a parte invisível do iceberg. Ao contrário do que se pode imaginar, a boa vontade do responsável pelo acolhimento, seu sorriso e sua amabilidade de nada adiantam se a reserva foimalfeita e se ocliente não sente receber aquilo que lhe prometeram em todos os locais de serviço. A qualidade da relação pode minimizar a desilusão do cliente e acalmar a sua cólera, mas, não apaga o erro e não compensa a falta de profissionalismo e a falta de método. O acolhimento deve ser cortês e alegre, mas, sobretudo, ele deve ser eficaz. Esta eficiência se obtém com uma boa organização do serviço de recepção que é amplo, indo além da portaria, com a análise das tarefas a serem realizadas e um estudo dos procedimentos para o acolhimento amplo. Não se pode deixar na dependência do humor de cada um a faculdade de bem ou (mal) acolher. Deve-se fazer de tal maneira que todos os clientes sejam sempre bem-acolhidos por todos. A qualidade do acolhimento depende tanto do ser humano quanto, também, da qualidade da organização dos serviços, do cuidado com que foram programados os detalhes, das condições nas quais trabalham os responsáveis pelo acolhimento etc. (Gouirand, 1994: 43-52).

\section{Sorriso-Sorrir}

Para muitos, bem acolher é sorrir. O sorriso parece ser uma panacéia que arranja tudo ou quase tudo e que pode, às vezes, fazer aceitar prestações de serviço medíocres. Ao contrário, mesmo quando tudo está perfeito, um acolhimento sem sorriso não é nunca muito bom. É um dos aspectos mais misteriosos do acolhimento. O verdadeiro sorriso, autêntico, é um fenômeno puramente fisiológico, é o resultado de uma excitação moderada que produz no homem o prazer. Esta excitação se exprime em todo o sistema muscular, mas, como ela é moderada, coloca em movimento somente os músculos mais móveis do corpo que são, no homem, os músculos da face. Dessa forma, o sorriso é o sinal do prazer e da felicidade, pois há uma associação mecânica entre os dois, enquanto um rosto mole e caído, sem tônus, exprime o desinteresse, o aborrecimento, o sofrimento. O sorriso espontâneo, que é o sorriso original, um sorriso refletido, se produz, infelizmente, muito raramente. Ele aparece efetivamente quando o prazer sentido é suficientemente forte para colocar em movimento nossos músculos.

O sorriso do acolhimento é o sorriso que expressa prazer, o sinal da felicidade é linguagem. Ele diz, ele clama: "Eu estou feliz de ver/receber você". É o modo privilegiado de comunicar o acolhimento. O sorriso é a primeira resposta às expectativas do viajante, ele é o sinal de reconhecimento. Quando sorrimos para aquele que chega, isto significa que o identificamos. É para ele que sorrimos, não para uma outra pessoa. O viajante não é mais um ser anônimo, ele tornou-se uma pessoa que é "bem-vinda". O sorriso comunica que aquele que era desconhecido é agora aceito na comunidade. O sorriso é, também, sinal de fraternidade; en fim, sinal de "cuidado". Ele acalma as angústias daquele que chega e receia ser mal recebido. Por analogia, o sorriso de acolhimento é percebido como o sorriso da mãe, feliz de ver seu filho. Contém a promessa de ser cuidado, de proteção, de carinho. O sorriso resume toda a mensagem do acolhimento, por isso é confundido com o acolhimento. O sorriso espontâneo, sincero é um elemento determinante do acolhimento profissional. Graças a ele, passamos do acolhimento indiferente a um acolhimento personalizado. O sorriso é tão importante que não podemos deixá-lo na dependência do "humor" daquele que recepciona. A ausência de sorriso pode custar muito caro a uma empresa. Quando o responsável pelo acolhimento se recusa voluntariamente a sorrir, ele comete uma grave falta profissional (Gouirand, 1994:129-138).

\section{Local do Acolhimento ao Turista}

Reconhecer o enorme papel dos aspectos psicológicos no acolhimento não significa negligenciar a importância do local e do ambicnte matcrial. Um c outro são indissociáveis e cada um influencia o outro. O cuidado dado, por aquele que acolhe, à preparação e ao embelezamento do espaço do acolhimento é tão significativo quanto a qualidade da relação que se estabelece no momento do acolhimento. Ser acolhido num local agradável, bem climatizado, bem decoradojá é um sinal de bom acolhimento para o cliente.

Desta forma, a arquitetura para o acolhimento requer que os espaços tenham dimensão "humanizada". As palavras-chave neste aspecto sãomedida e equilíbrio, um equilibrio entretrês pontos: espaço, homem e função. Para que se chegue ao "ambiente de acolhimento", os espaços devem ser funcionais, a escolha dos materiais deve considerar dois dos principais elementos sensoriais do acolhimento: o calor humano eum prazer delicado.Outros pontos importantes são a decoração, iluminação, higiene, limpeza e manutenção dos espaços; os odores, os sons (a música), o conforto sensorial, representado por estímulos agradáveis (Gouirand, 1994:139-150)

O ambiente tem a sua linguagem própria, é em si mesmo um discurso, uma mensagem que implica promessa de bem-estar, de conforto, de acolhimento.

\section{Perfil e Formaçāo do Pessoal para o Acolhimento ao Turista}

Aquele que acolhe é parte integrante do espaço em que acolhe e da atmosfera que aí reina. Não há, então, um arquétipo físico do pessoal do acolhimento, mas há 
uma vantagem quando o físico de quem acolhe está em harmonia com o local onde ele exerce o seu métier. Deve haver um tipo de entendimento entre o pessoal para o acolhimento, o tipo de hotel e a motivação da clientela. A primeira impressão daquele que chega é visual, e a expressão, postura e compostura daquele que acolhe não é neutra, sem função, pelo contrário tem função significativa, é a primeira mensagem do hotel para o cliente.

Estar numa função de acolhimento num hotel implica possuir um certo número de qualidades naturais. O responsável pelo acolhimento deve estar "aberto para os outros". Esta é uma das suas qualidades principais, porém deve estar acompanhada de outras qualidades também importantes, tais como: bom equilíbrio psicológico, boa aptidão comunicativa, calma e mesura, certa elegância nas atitudes e a perseverança e vontade de fazer bem.

No que concerne a sua formação, o pessoal do acolhimento deve receber dois tipos de formação: uma geral (cultura geral, base de todo conhecimento; o saber viver, as regras de protocolo, as regras de boa apresentação e as de comunicação); e a outra específica que deve ter por base que o acolhimento hoteleiro é responsabilidade de todos os setores, uma vez que o cliente passa a maior parte de seu tempo no restaurante, no bar, no café da manhã, nos salões de congressos, do que na recepção ou no caixa. No entanto, quando se fala de acolhimento, pensa-se somente na recepção, no hall e na portaria social. É imprescindível compreender que todos os serviços são responsáveis e que cada colaborador deve ser formado adequadamente. Para bem acolher profissionalmente, é necessário tanto conhecer os mecanismos psicológicos mobilizados pelo acolhimento, quanto ter um certo número de qualidades naturais e desenvolvê-las. Estar perfeitamente integrado à empresa para a qual trabalhamos e, sobretudo, ter vontade de aperfeiçoar-se permanentemente para melhor se comunicar com os outros, operando o e no processo de acolhimento (Gouirand, 1994:159-168)

\section{Consideraçōes Finais}

Com esta abordagem global sobre o acolhimento, parece evidente que se trata de um processo e não apenas de uma ação pontual a cargo de algumas pessoas, e a sua possível influência sobre o fluxo de turistas aos diferentes destinos Salientamos a maneira como o acolherdeveria ser valorizado técnica e afetivamente, por meio da tomada de consciência de variados processos que intervêm neste importante momento para o turista: o seu acolhimento no destino que escolheu para desfrutar as suas férias ou para desempenhar suas atividades profissionais. Para finalizar destaca-se que o acolhimento deve acompanhar todas as ações que implicam a relação com o cliente, inclusive os atos de encerramento, pois a última expressão não deve ser o "adeus", mas sim o "volte logo. continuaremos de braços abertos para acolhê-lo". Dessa forma, planta-se no cliente a semente do desejo de voltar, pois ele lembrará sempre de que foi e será bem acolhido, transformando-se assim em cliente permanente. Enfim, a fidelidade é o "laço que nos unirá neste mundo de competição que reconhecemos e nos estimula a vencer" pela qualidade do acolhimento oferecido como promessa inicial e cumprido como compromisso permanente.

\section{Referências Bibliográficas}

BENI, Mario C. 2000. Análise estrulural do turismo. São Paulo: SENAC

GOUIRAND, Pierre. 1984. L Accich Hordicr. Fince, Paris: Editions BPI. 1396. Le Concept d'Accueil - Reconnaissance, Hospitalité et Matemage. Les Cahiers lispaces, France, n. 48, p.
134-141.

Recebido em 6/4/2001 